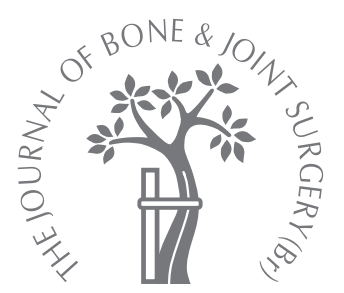

A. Afshar

From Urmia

University of Medical

Sciences, Urmia, Iran

- CASE REPORT

\title{
Ulnar dimelia without duplicated arterial
} anatomy

\begin{abstract}
In this case report a four-year-old girl with ulnar dimelia is described. She had six digits without mirror symmetry in her right hand. The first pre-axial digit was excised and true pollicisation performed for the second pre-axial digit. The arterial anatomy was abnormal but there was not symmetrical development of the arterial tree.
\end{abstract}

Ulnar dimelia is characterised by duplication of the ulna, absence of the radius and thumb and polydactyly. The incidence is unknown since it is such a rare congenital anomaly. ${ }^{1}$ There have been only a few earlier reports in the literature. ${ }^{2-14}$

In typical ulnar dimelia, the forearm and hand elements show a degree of sagittal mirror symmetry. However, variants of the anomaly without an axis of symmetry have been reported. ${ }^{2,5,11,12,14}$ Limited movement of the elbow and a flexion deformity of the wrist are some of the associated features. ${ }^{2-14}$ The aim of treatment is functional and aesthetic improvement. Reduction of the number of digits and thumb reconstruction are the mainstays of treatment. ${ }^{15}$

This case is reported because of the extreme rarity of the condition.

\section{Case report}

A four-year-old girl presented with a congenital abnormality of the right upper limb (Fig. 1). She was the first child of a non-consanguineous family and was a full-term, normal vaginal delivery. There were no pre- or other postnatal medical problems and no family history of congenital musculoskeletal anomalies. The main parental concern was the appearance of the hand and the presence of the extra digit. The right elbow appeared to be enlarged and showed an active range of movement from $30^{\circ}$ to $90^{\circ}$. There was no active supination or pronation of the forearm. The passive supination of the right forearm was $0^{\circ}$ to $30^{\circ}$ and pronation was restricted. The right upper limb was $3 \mathrm{~cm}$ shorter than the left. The right wrist was deviated laterally (radially) and held in flexion, but showed weak dorsiflexion to neutral. The left hand was dominant, but she was able to use the right hand for assistance. She was able to grasp objects with all the fingers of her right hand, which had six digits arranged in two groups (Fig. 2). The pre-axial group comprised two digits and the post-axial group four. The pre-axial two digits, located in the position of the absent thumb, were in some opposition to the post-axial four digits (Fig. 3). The web space between the two groups of digits was enlarged. All the digits were held in flexion, but active extension was possible and the two groups of digits could function independently. Restriction of the pre- or post-axial group movements by the examiner did not limit the movement of the other group. This may have been indicative of a separate set of extrinsic muscles acting upon the two groups.

The post-axial four digits, except the most medial, were relatively normal in appearance. The last digit had a camptodactyly deformity at the proximal interphalangeal (PIP) joint. The thenar prominence was absent. The PIP joint of the first pre-axial digit had symphalangism. The parents indicated that the second pre-axial digit functioned better than the others. Radiographs of the forearm showed two ulnae, but no radius. At the elbow the duplicated ulnae faced each other and articulated with the distal humerus separately. At the wrist there were four ossification centres. The secondary ossification centre in the distal epiphysis of the medial ulna was apparent, while that in the distal epiphysis was not. This may have indicated a delay in the development of the ossification centres on the lateral side. Each digit had three phalanges and its own metacarpal.

CT angiography was performed to assess the vascular anatomy of the limb (Fig. 4). The arterial tree was not duplicated. The brachial artery continued as the ulnar artery 


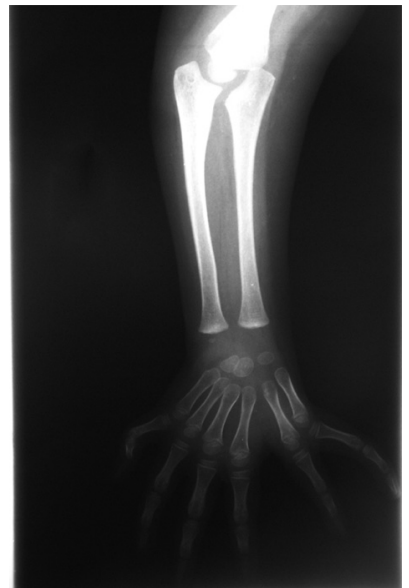

Fig. 1

Radiograph showing ulnar dimelia with six digits in a four-yearold girl.

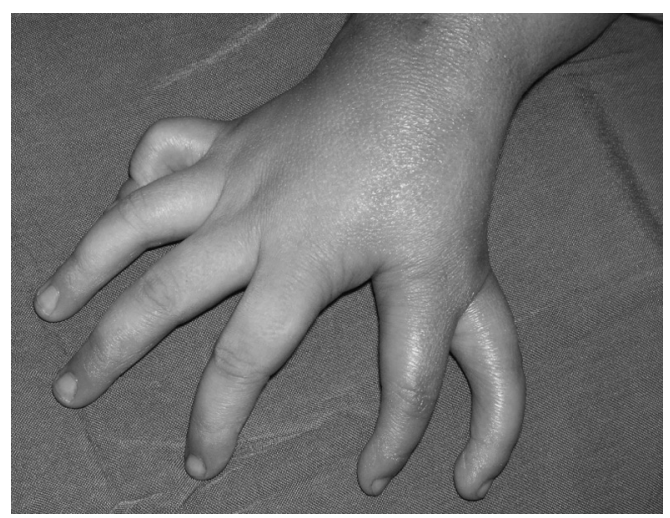

Fig. 2

Photograph of the asymmetrical mirror hand showing six digits arranged in two groups.

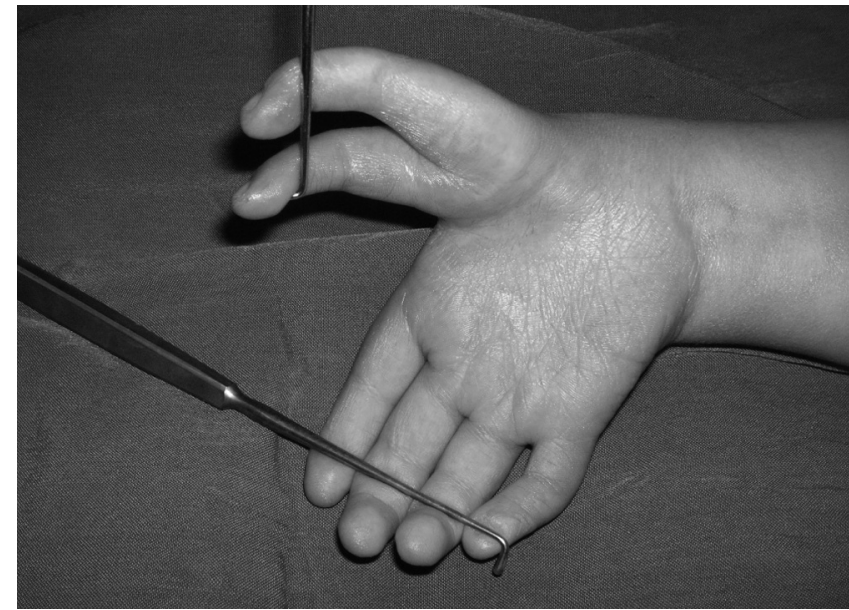

Fig. 3

Photograph showing that the pre-axial two digits, located in the position of the absent thumb, were in some opposition to the post-axial four digits.

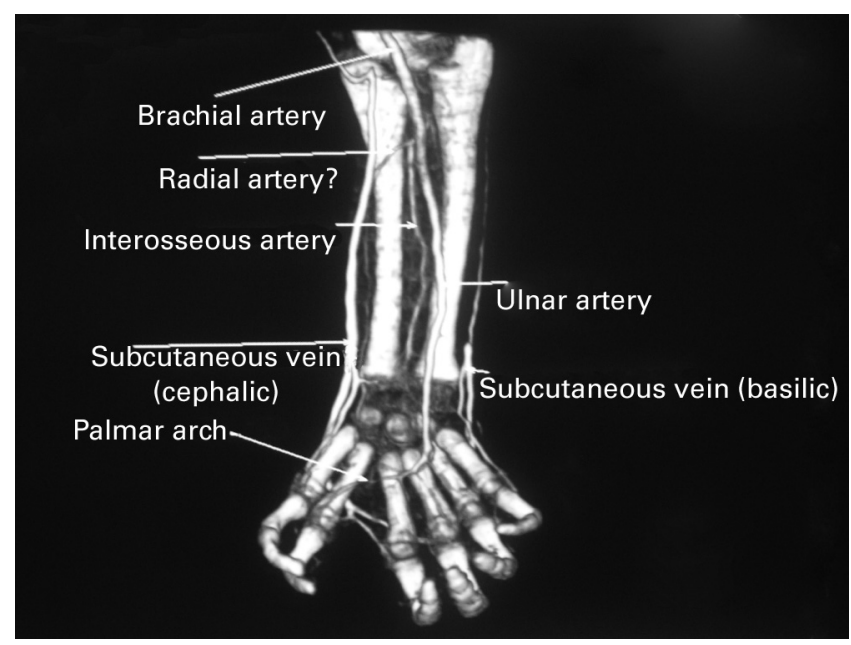

Fig. 4

CT angiograph of the limb.

which was the dominant artery in the forearm. In the proximal forearm the ulnar artery separated into the interosseous artery and an attenuated radial artery which ended at the level of the wrist. The ulnar artery continued in the hand as the superficial palmar arch which supplied all the pre- and post-axial digits. No deep palmar arch was detected.

For surgical management the first pre-axial digit was excised and the second was pollicised. The principles of true pollicisation (transfer of a digit on its neurovascular pedicle with shortening, transposition and rotation of the digit) were followed. ${ }^{4}$ Tissues belonging to the amputated digit were used to reconstruct the new thumb.

Each of the pre-axial digits had two flexor tendons and medial and lateral interossei. Each deep flexor had a corresponding lumbrical muscle. There was a normal extensor mechanism over the metacarpophalangeal joints and the proximal phalanges of the two pre-axial digits although the extensor tendons were hypoplastic.

The interossei muscles were rearranged such that the lateral and medial interossei of the excised first pre-axial digit, as well as the lateral interosseous muscle of the second pre-axial digit, were transferred to act together as the abductor pollicis brevis and occupied the thenar area. The medial interosseous muscle of the second preaxial digit was transferred to act as the thumb adductor. The superficial flexor tendon of the amputated digit was transferred to act as the abductor pollicis longus. The deep flexor tendon of the excised digit was used to reinforce the extensor of the thumb. 


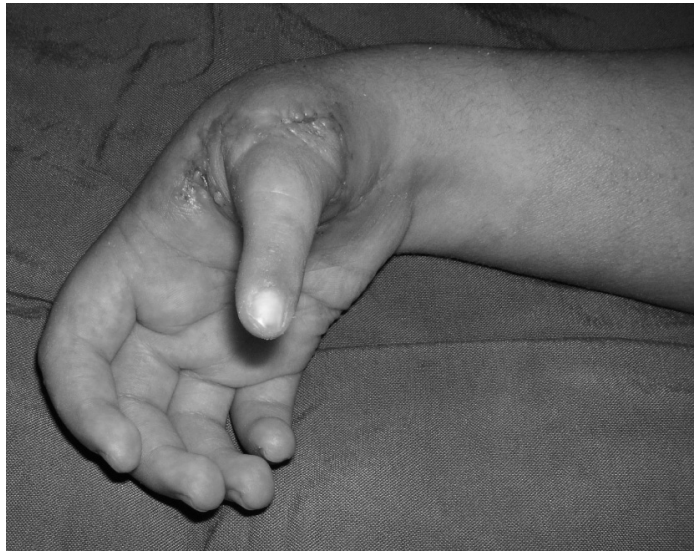

Fig. 5

Photograph of the hand four weeks after pollicisation.

A cock-up splint was used to support the wrist during the healing process. The parents were satisfied with the appearance of the new thumb and the hand (Fig. 5).

\section{Discussion}

The first dissection of a cadaver with ulnar dimelia, which has been preserved in the Warren Anatomical Museum at Harvard University Medical School, shows an asymmetrical arterial supply. The artery on the lateral side of the wrist supplied the lateral two and a half digits and the medial or normal ulnar artery supplied the medial four and a half digits. There was no connection between these two major supplying arteries. ${ }^{1,3}$ Gropper $^{8}$ performed pollicisation in a mirror hand and reported that the vessels appeared to be normal. Barton et $\mathrm{al}^{4}$ found that the blood vessels to the digit which was to be pollicised were abnormal and so performed the procedure on a single arterial pedicle. In the case described here, investigation of the vascular anatomy of the abnormal limb revealed that the distribution of the arterial supply was abnormal and asymmetrical. The superficial palmar arch, derived from the ulnar artery, supplied all including the pre-axial digits. The interosseous artery and the attenuated radial artery ended at the level of the wrist. Although this finding may not necessarily apply to ulnar dimelia it has considerable surgical significance, especially when performing pollicisation.

A classical ulnar dimelia has some symmetry about the midline. Non-classical ulnar dimelia, however, lacks symmetry in both the forearm and the digits. In the latter, the forearm may contain an ulna and a radius, or even three bones (ulna/ radius/radius or ulna/ulna/radius). ${ }^{3,5,11}$ Although seven ${ }^{3,10}$ or eight ${ }^{2,5,11-14}$ digits are usual, patients with six ${ }^{7,9}$ or even five digits ${ }^{6}$ have been reported.

Al-Qattan et $\mathrm{al}^{2}$ published a descriptive classification for the mirror hand, mainly based on the bony morphology of the forearm. ${ }^{2}$ Two major concerns in the treatment of ulnar dimelia are the excision of extra digits and the reconstruction of a new thumb. ${ }^{1,15}$ The classification does not describe the hand itself. Features such as the number of digits, the position (opposable/non-opposable), any digital deformities, and the size of the first web space must be determined. Other features may include limited movements of the elbow, forearm and wrist and a flexion contracture of the wrist. There are also reports of extension of the abnormality above the elbow, even involving the upper arm and shoulder. ${ }^{3,7,11,13}$

Most cases of ulnar dimelia are sporadic although Sandrow, Sullivan and Steel ${ }^{16}$ and Martin, Jones and Jones ${ }^{17}$ described associated genetic syndromes. The development of the pre/post-axial (radio-ulnar) plane of the limb is controlled by a group of mesenchymal cells called the zone of polarising activity. This is located in the posterior margin of the limb bud and functions as a signalling centre for anteroposterior limb development. ${ }^{1,2,15}$ The signals diffuse toward the pre-axial margin and its concentration gradient determines the morphology of the tissues. ${ }^{1,2,15}$ Summerbell ${ }^{18}$ placed an impermeable barrier in the limb bud and divided the early chick limb bud into anterior (pre-axial) and posterior (post-axial) portions and development continued on only one side.

Failure of the morphogenesis signals to reach the preaxial side of the limb may result in radial longitudinal deficiency. ${ }^{6,19}$ A maximum concentration of signals on the pre-axial side produces ulnar dimelia. Experiments have shown that a mirror duplication anomaly can be produced by transplantation of the zone of polarising activity to the radial side of the limb. ${ }^{1,15,20,21}$

An altered balance of the inductive signals across the radio-ulnar plane produces different forms of the anomaly. ${ }^{2}$ King and Hoyes ${ }^{12}$ and Yang et $\mathrm{l}^{14}$ presented two patients each with one ulna and a well-formed radius. Al-Qattan et $\mathrm{al}^{2}$ presented a patient with one ulna and a hypoplastic radius. Two patients with two ulnae (one of the ulnae was vestigial) and a hypoplastic radius were reported by Jafari and Sharif, ${ }^{11}$ while Barton et $\mathrm{al}^{3}$ and Bhaskaranand et $\mathrm{al}^{5}$ reported one patient each with one ulna and two hypoplastic radii.

Classification of the mirror hand as ulnar dimelia is derived from the hypothesis that the development of the more distal segment of the limb is determined by the more proximal segments. ${ }^{10,13}$ The prominent obvious feature of ulnar dimelia is polydactyly, the anomaly usually being described as a duplication. However, it cannot be considered to be a pure duplication. Gorriz ${ }^{9}$ and Chinegwundoh et $\mathrm{al}^{6}$ explained the anomaly as a failure of anteroposterior differentiation. King and Hoyes ${ }^{12}$ believed that the anomaly arose from aplasia and a failure of development.

Ulnar dimelia may be produced by the transplantation of the zone of polarising activity to the lateral side of the limb or altered inductive interactions of its signals. ${ }^{2}$ It seems appropriate that it should be considered as a problem of formation rather than a duplication or failure of differentiation. 
No benefits in any form have been received or will be received from a commercial party related directly or indirectly to the subject of this article.

\section{References}

1. Barton N. Mirror hand. In: Buck-Gramcko D, ed. Congenital malformation of the hand and forearm. London: Churchill Livingstone, 1998:271-7.

2. Al-Qattan MM, Al-Thunayan A, De Cordier M, Nandagopal N, Pikaanen J. Classification of the mirror hand: multiple hand spectrum. J Hand Surg $[\mathrm{Br}]$ 1998;23:534-6.

3. Barton NJ, Buck-Gramcko D, Evans DM. Soft tissue anatomy of mirror hand. $J$ Hand Surg [Br] 1986;11:307-19.

4. Barton NJ, Buck-Gramcko D, Evans DM, et al. Mirror hand treated by true pollicization. J Hand Surg [Br] 1986;11:320-36.

5. Bhaskaranand K, Bhaskaranand $\mathbf{N}$, Bhat AK. A variant of mirror hand: a case report. J Hand Surg [Am] 2003;28:678-80.

6. Chinegwundoh JOH, Gupta M, Scott WA. Ulnar dimelia: is it true duplication of the ulna? J Hand Surg [Br] 1997;22:77-9.

7. De Smet L. Ulnar dimelia. Acta Orthop Belg 1999;65:382-4.

8. Gropper PT. Ulnar dimelia. J Hand Surg [Am] 1983;8:487-91.

9. Gorriz G. Ulnar dimelia: a limb without anteroposterior differentiation. J Hand Surg [Am] 1982;7:466-9
10. Harrison RG, Pearson MA, Roaf R. Ulnar dimelia. J Bone Joint Surg [Br] 1960;42B:549-55.

11. Jafari D, Sharifi B. A variant of mirror hand: a case report. J Bone Joint Surg $[\mathrm{Br}]$ 2005;87-B:108-10.

12. King RJ, Hoyes AD. The mirror hand abnormality. Hand 1982;14:188-93

13. Pintilie D, Hatmanu D, Olaru I, Panzoa GH. Double ulna with symmetrical polydactyl: a case report. J Bone Joint Surg [Br] 1964;46-B:89-93.

14. Yang SS, Jackson L, Green DW, Weiland AJ. A rare variant of mirror hand: a case report. J Hand Surg [Am] 1996;21:1048-51.

15. Kozin SH. Embryology. In: Green DP, Hotchkiss RN, Pederson WC, Wolfe SW, eds Green's operative hand surgery. Fifth ed. Philadelphia-Churchill Livingstone, 2005:1375-9.

16. Sandrow RE, Sullivan PD, Steel HH. Hereditary ulnar and fibular dimelia with peculiar facies: a case report. J Bone Joint Surg [Am] 1970;52-A:367-70.

17. Martin RA, Jones MC, Jones KL. Mirror hands and feet with a distinct nasal defect: an autosomal dominant condition. Am J Med Genet 1993;46:129-31.

18. Summerbell D. The zone of polarizing activity: evidence for a role in normal chick limb morphogenesis. J Embryol Exp Morphol 1979;50:217-33.

19. James MA, McCarroll R, Manske PR. The spectrum of radial longitudinal deficiency: a modified classification. J Hand Surg [Am] 1999;24:1145-55.

20. Riddle RD, Tabin C. How limbs develop. Sci Am 1999;280:74-9.

21. Tabin CJ. Retinoids, homeoboxes and growth factors: toward molecular models for limb development. Cell 1991;66:199-217. 